\title{
Radionuclide imaging of jeopardized myocardium: From the beginning of the race to the finish line
}

\author{
Valeria Gaudieri, MD, PhD, ${ }^{\mathrm{a}}$ Carmela Nappi, MD, PhD, ${ }^{\mathrm{a}}$ and Mario Petretta, MD, \\ FAHA $^{\mathrm{b}}$ \\ a Department of Advanced Biomedical Sciences, University Federico II, Naples, Italy \\ b Department of Translational Medical Sciences, University Federico II, Naples, Italy
}

Received Sep 9, 2019; accepted Sep 9, 2019

doi: 10.1007/s12350-019-01897-4

See related article, pp. 1422-1434

Coronary artery disease is still a leading cause of morbidity and mortality and its prevalence is increasing. ${ }^{1}$ However, in the last three decades, the mortality rate due to ischemic heart disease has decreased significantly, although with wide differences between countries. This reduction is due to the decline in the incidence of ST-segment elevation myocardial infarction (STEMI) in association with a fall in acute and long-term mortality following STEMI thanks to the implementation of timely reperfusion, antithrombotic therapy, and secondary prevention. ${ }^{2}$

After the occlusion of an epicardial coronary artery, the myocardial area subtended by the occluded coronary artery is in jeopardy. This hypoperfused myocardium during the evolving myocardial infarction is defined as the area at risk (AAR). If ischemia persists with complete absence of blood flow, either antegrade or collateral, myocardial injury is meant to be irreversible leading to necrosis demarcation, with a wavefront progression from the subendocardium to the subepicardium. A timely reperfusion therapy may change the pathological features of myocardial infarction: coronary artery recanalization can avoid the transmural progression of myocardial necrosis and, most importantly, may

Reprint requests: Mario Petretta, MD, FAHA, Department of Translational Medical Sciences, University Federico II, Naples, Italy; petretta@unina.it

J Nucl Cardiol 2021;28:1435-7.

$1071-3581 / \$ 34.00$

Copyright (c) 2019 American Society of Nuclear Cardiology. stall necrosis evolution of AAR turning it in the salvaged myocardium. ${ }^{3}$

Quantifying how much myocardium is salvaged by measuring the final infarct size in relation to the initial AAR is mandatory to evaluate the efficacy of reperfusion therapy. Although a number of non-invasive imaging methods have been settled to evaluate myocardial salvage, namely ECG-based scoring systems, angiographic scores, cardiac magnetic resonance imaging (CMR), and more recently functional computed tomography, for a long time the most-used technique to quantify myocardial rescue has been single-photon emission-computed tomography (SPECT). Assessment of AAR by SPECT is done by injecting $99 \mathrm{~m}$-Technetium (Tc)-labelled perfusion tracers just before revascularization and then acquiring images up to 8 hours after the procedure. Therefore, this method requires tracer availability in the catheterization laboratory on a 24 hours basis and it can be logistically demanding. Evaluation of final infarct size requires repeated SPECT perfusion imaging in a stable state, at least 120 hours after infarction, and preferably weeksmonths following revascularization. ${ }^{4}$

It has been demonstrated that the degree of myocardial salvage assessed by SPECT is an independent predictor of outcome in patients with acute myocardial infarction. ${ }^{5}$

Moreover, SPECT perfusion imaging provides other useful information with diagnostic and prognostic value such as regional wall motion and thickening, ejection fraction and left ventricular geometry indices. ${ }^{6-8}$

Another tracer that can be used in the evaluation of AAR and of the extent of myocardial salvage is the ${ }^{123} \mathrm{I}$ $\beta$-methyliodo-phenyl pentadecanoic acid ( ${ }^{123} \mathrm{I}$-BMIPP). Rest imaging of ${ }^{123}$ I-BMIPP is related to its metabolism in the mitochondria. After an ischemic event, during the subacute phase ( $>6$ hours) there is a reduction of ${ }^{123} \mathrm{I}-$ 
BMIPP uptake in the affected territory, even after successful reperfusion therapy, with recover in the chronic phase (30 days). ${ }^{9}$ It has been demonstrated that the size of AAR assessed by ${ }^{123}$ I-BMIPP imaging at 7 days after myocardial infarction is similar to perfusion defect evaluated by SPECT perfusion imaging performed at cath lab time, with the advantage to being able to schedule the examination when the patient is more stable. $^{10}$

In the present issue of the Journal, Yoshida et al. ${ }^{11}$ compared the effect of prasugrel and clopidogrel on myocardial salvage, assessed by ${ }^{123}$ I-BMIPP imaging at 7 days after the reperfusion therapy and $99 \mathrm{~m}$-Tc-tetrofosmin SPECT 3 months after revascularization.

According to current guidelines, ${ }^{12,13}$ to reduce the risk of post-procedural thrombotic events, dual antiplatelet therapy (DAPT) consisting of aspirin in addition to a potent P2Y12 inhibitor (prasugrel or ticagrelor), or clopidogrel if these are not available or are contraindicated, is generally recommended for 12 months following percutaneous coronary intervention (PCI) for STEMI,. Prasugrel is currently the most-used drug due to its proven stability over time, which has been attributed to a fast and complete generation of its active metabolite ${ }^{14}$ Conversely, clopidogrel is not in the firstline therapy due to its variable effect on ADP-induced platelet aggregation, with an efficacy ranging from $0 \%$ to $100 \% .^{15}$

Polymorphisms of genes encoding cytochromes that are involved in generation of clopidogrel active metabolites influence the antiplatelet action of the drug. ${ }^{16}$ Several methods have been proposed to identify significant genetic variants, in particular in the CYP2C19 gene.

A recent paper reviewed the state-of-art of both platelet function and genetic testing for guiding $\mathrm{P}_{2} \mathrm{Y}_{12}$ receptor inhibitor therapy in PCI. ${ }^{17}$ These latter approaches may be useful when DAPT escalation or deescalation is an option; however, only one study demonstrated a benefit of tailoring the antiplatelet regimen according to platelet function testing. ${ }^{18}$ It should be considered that not only genetic variants affect clopidogrel activity but also other factors, such as gastrointestinal absorption, drug interactions, and therapy adherence are involved. Therefore, genotyping data cannot be considered a surrogate for platelet function test to assess antiplatelet response.

Yoshida et al. ${ }^{11}$ investigation has the merit to bring to the fore the discussion on the usefulness of platelet function tests, particularly in patients in whom DAPT is mandatory. It has been demonstrated that a high ontreatment platelet reactivity is associated with ischemic events while a low on-treatment platelet reactivity is associated with bleeding. ${ }^{19}$
In the current study, ${ }^{11}$ platelet function test was performed using a whole blood aggregometer based on the screen filtration pressure method. However, the prevalence of high and low-platelet reactivity may differ significantly between assays, and several laboratorybased methods, (Light Transmission Aggregometry, Multiple Electrode Aggregometry, Platelet Function Analyser (PFA)-100, Vasodilator-Stimulated Phosphoprotein (VASP) assay), and point-of-care or nearpatient-based assay (VerifyNow, Multiplate, Thromboelastography) have been proposed. ${ }^{20}$ Till now, no single test has been proven superior, although VerifyNow, PFA-100 and VASP are the most commonly used. Future trials are needed to determine the best method to analyze platelet function for clinical purpose, in particular in the setting of PCI.

Then again, the main finding of this study ${ }^{10}$ is that prasugrel in STEMI patients was associated with a higher degree of myocardial salvage compared with clopidogrel in the presence of high-platelet reactivity.

This is the first investigation of direct comparison between two P2Y12 inhibitors using SPECT imaging. However, other imaging techniques have been used to compare P2Y12 inhibitors efficacy.

In the REDUCE-MVI ${ }^{21}$ study, CMR was performed during the acute phase and at 1 month in 110 patients with STEMI treated with a loading dose $(180 \mathrm{mg})$ of ticagrelor and randomized to maintenance therapy of ticagrelor or prasugrel after primary PCI. The Authors found that ticagrelor maintenance therapy was not superior to prasugrel in preventing coronary microvascular injury in the infarct-related territory as assessed by the index of microcirculatory resistance, and this resulted in a comparable infarct size at 1 month. In a subgroup of 94 patients (85\%), no differences in platelet inhibition and high and low-platelet reactivity were observed between the 2 treatment groups after 1 month of maintenance therapy.

Non-invasive imaging methods are widely used to estimate and to monitor therapy effects and efficacy. Thus, there is great interest in consistent techniques development that may provide standardized measurements of therapy effect translating imaging findings themselves into surrogate end-points for outcome prediction. All this effort takes as finish line a personalized approach to timely optimal therapy for ever more patient-tailored precision medicine.

\section{Disclosure}

Valeria Gaudieri, Carmela Nappi, and Mario Petretta declare that they have no conflict of interest. 


\section{References}

1. Benjamin EJ, Blaha MJ, Chiuve SE, Cushman M, Das SR, Deo R, American Heart Association Statistics Committee and Stroke Statistics Subcommittee, et al. Heart disease and stroke statistics2017 update: A report from the american heart association. Circulation 2017;135:e146-603. https://doi.org/10.1161/cir.00000000 00000485 .

2. Ibanez B, James S, Agewall S, Antunes MJ, Bucciarelli-Ducci C, Bueno H, ESC Scientific Document Group, et al. 2017 ESC Guidelines for the management of acute myocardial infarction in patients presenting with ST-segment elevation: The Task Force for the management of acute myocardial infarction in patients presenting with ST-segment elevation of the European Society of Cardiology (ESC). Eur Heart J 2018;39:119-77. https://doi.org/10. 1093/eurheartj/ehx393.

3. Ibáñez B, Heusch G, Ovize M, Van de Werf F. Evolving therapies for myocardial ischemia/reperfusion injury. J Am Coll Cardiol 2015;65:1454-71. https://doi.org/10.1016/j.jacc.2015.02.032.

4. Bøtker HE, Kaltoft AK, Pedersen SF, Kim WY. Measuring myocardial salvage. Cardiovasc Res 2012;94:266-75. https://doi. org/10.1093/cvr/cvs081.

5. Ndrepepa G, Mehilli J, Schwaiger M, Schühlen H, Nekolla S, Martinoff $S$, et al. Prognostic value of myocardial salvage achieved by reperfusion therapy in patients with acute myocardial infarction. J Nucl Med 2004;45:725-9.

6. Nappi C, Gaudieri V, Cuocolo A. Behind traditional semi-quantitative scores of myocardial perfusion imaging: An eye on niche parameters. Eur Cardiol 2019;14:13-7. https://doi.org/10.15420/ec r.2019.5.1.

7. Petretta M, Acampa W, Daniele S, Zampella E, Assante R, Nappi $\mathrm{C}$, et al. Long-term survival benefit of coronary revascularization in patients undergoing stress myocardial perfusion imaging. Circ $\mathrm{J}$ 2016;80:485-93. https://doi.org/10.1253/circj.CJ-15-1093.

8. Gaudieri V, Nappi C, Acampa W, Zampella E, Assante R, Mannarino $\mathrm{T}$, et al. Added prognostic value of left ventricular shape by gated SPECT imaging in patients with suspected coronary artery disease and normal myocardial perfusion. $J$ Nucl Cardiol 2019;26:1148-56. https://doi.org/10.1007/s12350-017-1090-x.

9. Nappi C, Gaudieri V, Petretta M. Simultaneous dual-tracer (99m)Tc-tetrofosmin and (123)I-BMIPP acquisition with CZT for ischemic memory: The future approaches to image the past. J Nucl Cardiol 2019. https://doi.org/10.1007/s12350-019-01614-1.

10. Tanaka R, Nakamura T. Time course evaluation of myocardial perfusion after reperfusion therapy by $99 \mathrm{mTc}$-tetrofosmin SPECT in patients with acute myocardial infarction. J Nucl Med 2001;42:1351-8

11. Yoshida R, Takagi K, Ishii H, Morishima I, Tanaka A, Morita Y, et al. Myocardial salvage after ST-segment-elevation myocardial infarction: Comparison between prasugrel and clopidogrel in the presence or absence of high-residual platelet reactivity. J Nucl Cardiol 2019. https://doi.org/10.1007/s12350-019-01852-3.

12. Neumann FJ, Sousa-Uva M, Ahlsson A, Alfonso F, Banning AP, Benedetto U, ESC Scientific Document Group, et al. 2018 ESC/
EACTS Guidelines on myocardial revascularization. Eur Heart J 2019;40:87-165. https://doi.org/10.1093/eurheartj/ehy394.

13. Levine GN, Bates ER, Bittl JA, Brindis RG, Fihn SD, Fleisher LA, et al. 2016 ACC/AHA guideline focused update on duration of dual antiplatelet therapy in patients with coronary artery disease: A report of the American College of Cardiology/American Heart Association Task Force on Clinical Practice Guidelines. J Am Coll Cardiol 2016;68:1082-115. https://doi.org/10.1016/j.jacc.2016.03. 513.

14. Braun OO, Johnell M, Varenhorst C, James S, Brandt JT, Jakubowski JA, et al. Greater reduction of platelet activation markers and platelet-monocyte aggregates by prasugrel compared to clopidogrel in stable coronary artery disease. Thromb Haemost 2008;100:626-33.

15. Aleil B, Ravanat C, Cazenave JP, Rochoux G, Heitz A, Gachet C. Flow cytometric analysis of intraplatelet VASP phosphorylation for the detection of clopidogrel resistance in patients with ischemic cardiovascular diseases. J Thromb Haemost 2005;3:85-92.

16. Hulot JS, Bura A, Villard E, Azizi M, Remones V, Goyenvalle C, et al. Cytochrome P450 2C19 loss-of-function polymorphism is a major determinant of clopidogrel responsiveness in healthy subjects. Blood 2006;108:2244-7.

17. Sibbing D, Aradi D, Alexopoulos D, Ten Berg J, Bhatt DL, Bonello L, et al. Updated expert consensus statement on platelet function and genetic testing for guiding P2Y(12) receptor inhibitor treatment in percutaneous coronary intervention. JACC Cardiovasc Interv 2019;12:1521-37. https://doi.org/10.1016/j.jcin.2019. 03.034 .

18. Sibbing D, Aradi D, Jacobshagen C, Gross L, Trenk D, Geisler T, TROPICAL-ACS Investigators, et al. Guided de-escalation of antiplatelet treatment in patients with acute coronary syndrome undergoing percutaneous coronary intervention (TROPICAL-ACS): A randomised, open-label, multicentre trial. Lancet 2017;390:174757. https://doi.org/10.1016/s0140-6736(17)32155-4.

19. Tantry US, Bonello L, Aradi D, Price MJ, Jeong YH, Angiolillo DJ, Working Group on On-Treatment Platelet Reactivity, et al. Consensus and update on the definition of on-treatment platelet reactivity to adenosine diphosphate associated with ischemia and bleeding. J Am Coll Cardiol 2013;62:2261-73. https://doi.org/10. 1016/j.jacc.2013.07.101.

20. Leunissen TC, Janssen PW, Ten Berg JM, Moll FL, Korporaal SJ, de Borst GJ, et al. The use of platelet reactivity testing in patients on antiplatelet therapy for prediction of bleeding events after cardiac surgery. Vascul Pharmacol 2016;77:19-27. https://doi.org/ 10.1016/j.vph.2015.12.002.

21. van Leeuwen MAH, van der Hoeven NW, Janssens GN, Everaars H, Nap A, Lemkes JS, et al. Evaluation of microvascular injury in revascularized patients with ST-segment-elevation myocardial infarction treated with ticagrelor versus prasugrel. Circulation 2019;139:636-46. https://doi.org/10.1161/CIRCULATIONAHA.1 18.035931 .

Publisher's Note Springer Nature remains neutral with regard to jurisdictional claims in published maps and institutional affiliations. 